\title{
O papel das redes na formação do movimento indígena em Mato Grosso do Sul
}

\section{The role of the networks in the rise of the indigenous movement in Mato Grosso do Sul, Brazil}

Resumo: A articulação em redes tornou-se com o advento da sociedade informacional uma das principais características dos movimentos sociais contemporâneos. Os movimentos sociais indígenas também articulam-se em redes com outros movimentos sociais e outras entidades da sociedade civil. No caso dos povos indígenas de Mato Grosso do Sul, porém, por conta de suas condições sociais específicas, como a situação de excepcional vulnerabilidade, a incidência do poder tutelar como forma intensiva de controle dos povos e desestruturação de sua organização social e cultural, além das condições específicas da transformação da resistência étnica em ação política nos termos em que esta existe no Ocidente, fazem do recurso à articulação em redes uma estratégia portadora de muitas especificidades. No Mato Grosso do Sul, a articulação dos povos indígenas em redes foi decisiva para a transformação dos processos de resistência étnica para uma forma de resistência e luta na forma sociológica de movimento social. A associação em redes apresenta-se de três formas: a articulação entre diferentes parentelas do mesmo grupo étnico, entre diferentes povos e entre estes e entidades civis e setores do Estado.

Palavras-chave: Guarani Ñandeva; Kaiowá; Terena.

Abstract: The articulation in networks became with the advent of the informational society one of the main characteristics of the contemporary social movements. Indigenous social movements, which emerge during the same period in which the

\footnotetext{
* Professor Adjunto do Departamento de Filosofia e Ciências Humanas da Universidade Federal do Amapá - DFCH/UNIFAP. Pós-Doutorando pelo Programa de Pós-Graduação em História da Universidade Federal do Amapá - PPGH/UNIFAP. Doutor em Geografia - IESA/UFG. Cientista Social, Mestre em Sociologia.
} 
Revista Brasileira de História \& Ciências Sociais - RBHCS

Vol. 13 No 25, Edição Especial de 2021

information society is consolidated, are also articulated in networks with other social movements and other entities of civil society. In the case of the indigenous peoples of Mato Grosso do Sul, however, due to their specific social conditions, such as the situation of exceptional vulnerability, the incidence of tutelar power as an intensive form of control of the peoples and the destructuring of their social and cultural organization, besides of the specific conditions of the transformation of ethnic resistance into political action as it exists in the West, make the use of networking in this case a phenomenon with determinations and way of being bearer of many specificities. In Mato Grosso do Sul, the articulation of indigenous peoples in networks was decisive for the transformation of the processes of ethnic resistance to a form of resistance and struggle in the sociological form of social movement. The association in networks presents itself in three ways: the articulation between different leaderships of the same ethnic group, between different peoples and between these and civil entities and sectors of the State.

Keywords: Guarani Ñandeva; Kaiowá; Terena.

\section{INTRODUÇÃO}

O objetivo deste artigo é refletir sobre as redes de alianças desenvolvidas pelo movimento indígena em Mato Grosso do Sul. Ao compreender a resistência indígena no estado como um movimento social, cabe aplicar-lhe o instrumental teórico de redes para interpretar as relações que estabelece com outros movimentos sociais e outros setores de sociedade civil.

Os movimentos sociais em geral intensificaram sua articulação em redes especialmente no fim do século XX, com o advento da sociedade informacional (CASTELLS, 2010), todavia, como veremos, as redes desempenharam e desempenham um papel sui generis no movimento indígena de Mato Grosso do Sul desde o seu surgimento. Adotamos a categoria de movimento indígena desenvolvida por Catherine González (2010), que, em resumo, identifica como componentes nucleares de uma resistência indígena feita em movimento social a realização de assembleias e ações de retomada e defesa do território. 
Revista Brasileira de História \& Ciências Sociais - RBHCS

Vol. 13 No 25, Edição Especial de 2021

Entende-se aqui por movimento indígena em Mato Grosso do Sul a mobilização sociopolítica realizada por quatro grupos étnicos: os Guarani Ñandeva e os Kaiowá, cuja mobilização data da virada da década de 1970-80; os Terena, cuja resistência começa ganhar forma de movimento social em 2003; e os Kinikinau, cujas raízes do movimento social remontam a 2003, porém se estabelece definitivamente no fim de 2014. Os Guarani Ñandeva e os Kaiowá constituem grupos étnicos distintos, entretanto, como realizam em conjunto uma mobilização política unitária, pode-se referir a um movimento social Guarani-Kaiowá, um movimento sociopolítico único, realizado em conjunto pelas duas etnias.

Como recurso metodológico para elucidação do papel das redes de alianças na formação do movimento sociopolítico indígena farei a análise do fenômeno no período de formação do movimento indígena de Mato Grosso do Sul. Ao recuperar a história de sua formação veremos como as redes de alianças formadas (1) entre diferentes grupos indígenas e (2) entre os povos indígenas e entidades da sociedade civil parceiras tiveram papel importantíssimo em sua formação como movimento social.

\section{O PARADIGMA DAS REDES DE MOVIMENTOS SOCIAIS}

O paradigma da sociedade em rede é inaugurado por Manuel Castells em sua trilogia A Sociedade Informacional. Segundo o autor, com o advento da sociedade informacional a partir do último quartel do século $\mathrm{XX}$, a forma societária fundamental passou a ser as relações sociais constitutivas de redes ${ }^{1}$.

Conforme Castells as redes são estruturas capazes de se expandir de forma ilimitada, desde que os novos elementos recém integrados compartilhem do mesmo código de comunicação da rede, que viabiliza sua integração. A rede assim tem um aspecto impositivo de fazer os elementos que querem nela inserir-se adaptarem-se ao tipo de comunicação específico de cada rede; outrossim, paradoxalmente, a atuação com vistas à autonomia frente à sociedade em rede necessita - para não ser engolida - articular-se em rede também. A rede, ao fim e ao cabo, é a única forma de

${ }^{1}$ Note-se que aqui falo de rede como uma forma de relação social, e não redes no sentido de "redes técnicas" ou "redes digitais". 
Revista Brasileira de História \& Ciências Sociais - RBHCS

Vol. 13 No 25, Edição Especial de 2021

sociabilidade possível para existir na sociedade informacional e para capitalizar poder o suficiente para influenciar o desenvolvimento social e a decisão política.

As redes passaram a ser a forma societária fundamental nesta nova sociedade. Incluso para os movimentos sociais a articulação em rede passou a ser a forma societária, organizativa e articulatória predominante.

After a decade of development of a new, global economy and of the decline of the nation-state in its transition to institutions of global governance, societies around the world have claimed their right to assert control over the emerging institutions. What started as resistance, based on identity, and preservation of the economic status quo, evolved into a multiplicity of projects, in which cultural identity, economic interests, and political strategies have combined in an increasingly complex pattern: the canvas of social movements in the network society. These movements, spreading throughout the world, have ended the neo-liberal fantasy of creating a new global economy independent of society by escaping into computer networks. The grand exclusionary scheme (explicit or implicit) of concentrating information, production, and markets in a valuable segment of the population, disposing of the rest in different forms, more or less humane according to each society's temper, has triggered, in Touraine's expression, a "grand refus"(CASTELLS, 2010, v.2, p. 166-7).

Como vemos da análise de Castells, movimentos sociais na sociedade informacional caracterizam-se de forma marcante pela oposição à exclusão das camadas populares da participação na direção da sociedade imposta pelo neoliberalismo. O que começou como uma resistência a essa exclusão tornou-se um complexo projeto social, político, econômico, cultural: o padrão dos movimentos sociais na sociedade em rede.

Para caracterizar os movimentos sociais na era informacional Castells desenvolve uma explicação para sua especificidade cujas raízes remontam a Alain Touraine.

Aujourd'hui, dans la société post-industrielle que j'ai nommée 'programmée', l'enjeu de ces luttes n'est pas l'utilisation sociale de la technique, mais celle de la production et de la diffusion massive des représentations, des informations et des langages (TOURAINE, 1992, p. 456-7).

Ambos concordam que na sociedade da segunda metade do século XX - a sociedade informacional para Castells, a sociedade pós-industrial, para Touraine - 
Revista Brasileira de História \& Ciências Sociais - RBHCS

Vol. 13 No 25, Edição Especial de 2021

os movimentos sociais projetam uma defesa das identidades culturais frente à imposição da lógica do mercado a toda a sociedade; em outros termos, contestam os caminhos de uma globalização imposta em prol da defesa de suas identidades sociais.

The first historical steps of informational societies seem to characterize them by the pre-eminence of identity as their organizing principle. I understand by identity the process by which a social actor recognizes itself and constructs meaning primarily on the basis of a given cultural attribute or set of attributes, to the exclusion of a broader reference to other social structures. Affirmation of identity does not necessarily mean incapacity to relate to other identities (for example, women still relate to men) or to embrace the whole society under such identity (for example, religious fundamentalism aspires to convert everybody). But social relationships are defined vis-a-vis the others on the basis of those cultural attributes that specify identity. (CASTELLS, 2010, v.1, p. 22).

Como a sociedade informacional decide e impõe a lógica do mercado para toda a sociedade e exclui grandes parcelas da sociedade de participação nesta decisão, movimentos sociais significam a sociedade se organizando para proteger as identidades e subjetividades culturais contra esta lógica esmagadora. Como tais os movimentos sociais formam redes - como forma de opor-se à imposição da lógica de mercado que também vem na forma de rede -, uma rede de interações de caráter global, que transcende e não considera as fronteiras nacionais nem o Estado-nação.

A novidade do pensamento de Castells é tratar a sociedade globalizada - um fenômeno tão desafiador aos cientistas sociais - como uma rede. Todos os fenômenos sociais nesta sociedade são compelidos e enquadrados na forma da articulação em rede. Assim igualmente para a existência e atuação específica dos movimentos sociais. Neste cenário do associativismo civil, cujo modo de ser é caracterizado pela articulação em rede, os movimentos sociais são compelidos a adotar esta forma de associação e tiram muito de sua força dela. Outrossim, os movimentos sociais não se articulam em redes apenas com outros movimentos sociais, porém articulam-se assim igualmente com outros organismos da sociedade civil.

Os movimentos indígenas, não obstante guardarem muitas especificidades em relação aos outros movimentos sociais, incorporam a forma associativa de redes e assim articulam-se como forma de ganho de poder social. Dito isto, a seções que se 
Revista Brasileira de História \& Ciências Sociais - RBHCS

Vol. 13 No 25, Edição Especial de 2021

seguem são um exercício sociológico de intepretação das alianças e parcerias desenvolvidas pelo movimento indígena de Mato Grosso do Sul por meio da categoria de redes.

\section{LINHAS GERAIS DA QUESTÃO INDÍGENA NO ESTADO DE MATO GROSSO DO SUL}

A resistência dos povos indígenas de Mato Grosso do Sul, assim como dos demais povos indígenas da Abya Yala, é frente ao processo de expropriação, esbulho territorial e subordinação, especialmente na forma do poder tutelar (FERREIRA, 2007), engendrado pela colonização da região. Ao todo atualmente são nove os povos indígenas remanescentes no estado e que seguem resistindo bravamente contra o genocídio: os povos Guarani Ñandeva, Kaiowá, Terena, Kinikinau, Kadiwéu, Guató, Ofaié, Atikum e Kamba.

Cada um destes povos passou por circunstâncias diferentes no processo de avanço das relações sociais capitalistas sobre a região; todavia, foram vítimas da mesma violência e subordinação colonial e expropriação capitalista. Malgrado tenham histórias singulares diferentes de expropriação e tenham realizado estratégias diferentes de resistência, o processo sociológico de subordinação, expropriação e exploração que os atingiu é basicamente o mesmo.

A política indigenista monocultural do estado nacional brasileiro, por meio do Serviço de Proteção ao Índio, visava a, e o fez, colocar os indígenas sob controle do Estado, por meio da instituição da tutela. Assim foram demarcadas as primeiras terras indígenas no Mato Grosso do Sul. O processo histórico de demarcação original dessas terras como podemos ver, não era o reconhecimento do direito indígena a vida e ao território. As primeiras demarcações, e todas que se seguiram, tinham como razão de ser abrir caminho para o avanço capitalista e de colonização, ou seja, permitir a expansão capitalista segura nas áreas ocupadas pelos povos indígenas. "O objetivo principal da política indigenista oficial, na primeira metade do século XX, era permitir a efetiva e segura expansão capitalista nas áreas ocupadas por populações indígenas" (URQUIZA, sem data); assegurar a posse brasileira às terras da região, no contexto da disputa com os países fronteiriços, e concentrar mão-de- 
Revista Brasileira de História \& Ciências Sociais - RBHCS

Vol. 13 No 25, Edição Especial de 2021

obra trabalhadora indígena, pelo que as reservas tiveram a função de concentrar exército industrial de reserva (FERREIRA, 2007, especialmente pp. 72-5 e pp. 3859).

Desde então, a demarcação de terras e criação de reservas indígenas tem sua lógica derivada deste poder tutelar e das finalidades de exploração econômica, ou seja, fazem parte da mesma política indigenista.

O regime tutelar e a política indigenista em geral tiveram como uma das características principais o desencadeamento de processos de territorialização. (...) Paralelamente aos processos de territorialização, se desenvolveu o projeto de inserção dos índios dentro da estrutura de classes da sociedade capitalista, em uma posição subalterna. (FERREIRA, 2007, p. 73).

Antes que se pense que as reservas foram demarcadas e garantidas pelo Estado como reconhecimento à dívida que tem com os Terena e os Kadiwéu, ou com alguma preocupação com os Kaiowá e Guarani, as demarcações e criações de reservas realizadas por iniciativa do estado sempre tiveram por baliza criar condições de melhor submeter os povos indígenas ao poder e ao controle do Estado, assegurar as condições para exploração capitalista segura e livre de impedimentos da região, e concentrar mão-de-obra indígena para trabalho nas usinas, fazendas e demais atividades, nas condições de exército industrial de reserva, ou seja, como força de trabalho passível de superexploração.

Diante deste quadro geral, reconhece-se evidentemente que nenhum povo indígena sobreviveu nem sobrevive sem árdua resistência; resistência ao extermínio, ao confinamento, à exploração, à subordinação. Porém, do ponto de vista específico da sociologia dos movimentos sociais, pode-se dizer inicialmente que os grupos étnicos Guarani, Kaiowá e Terena são o foco central da mobilização sociopolítica indígena no estado.

\section{A FORMAÇÃO DO MOVIMENTO INDÍGENA EM MATO GROSSO DO SUL}

$\mathrm{O}$ esforço indígena para reverter este quadro manifestou-se principalmente nas ações de retomadas de terras realizadas por estes grupos, e do início para cá até hoje as retomadas seguem ocupando posição significativa como estratégia de luta. 
Revista Brasileira de História \& Ciências Sociais - RBHCS

Vol. 13 No 25, Edição Especial de 2021

As primeiras ocupações de terra e ações de recuperação e defesa de seus territórios tradicionalmente ocupados no Mato Grosso do Sul, realizadas pelos índios Guarani e Kaiowá, ocorreram na passagem da década de 1970 para 1980.

Este dado é importantíssimo. As retomadas foram primeira estratégia de recuperação de territórios e, durante toda a trajetória do movimento e incluso atualmente, seguem sendo uma das principais formas de ação coletiva pela efetivação de direitos e pressão política. O crucial é que nas ações de recuperação de terras, tanto em seu início na década de 1970 quanto atualmente, já é visível o papel das redes estabelecidas e coordenadas pelos povos indígenas. Vejamos as primeiras ações de retomadas de terras, que caracterizam o surgimento do movimento sociopolítico dos povos indígenas em Mato Grosso do Sul.

Inaugura, segundo Levi Marques Pereira (2003), as retomadas como forma de ação coletiva e luta pelo território a comunidade Kaiowá Pirakuá, município de Bela Vista. O essencial é que a retomada como primeira e principal ação coletiva do movimento indígena de Mato Grosso do Sul só foi possível por conta de uma prévia articulação em rede pela comunidade Pirakuá.

O sucesso da mobilização em Pirakuá tornou sua forma de reivindicação retomada e aliança com outros grupos - paradigmática para outras comunidades indígenas que também viviam fora de seus territórios tradicionalmente ocupados e queriam recuperar suas terras.

Antônio Brand (2004) identifica no mesmo período a realização de retomadas indígenas no município de Paranhos, todavia com basicamente as mesmas características daquelas descritas por Pereira.

As primeiras ações de recuperação de espaços dos quais haviam sido expulsos, que obtiveram êxito, iniciam-se em 1978, na aldeia Takuaraty- Yvyvkuarusu, localizada no município de Paranhos. Os índios dessa área foram, por diversas vezes, expulsos e transferidos para áreas próximas, porém mantendo-se articulados, sempre retomavam. Quase simultaneamente a população das aldeias de Rancho Jacaré e Guaimbé, localizadas no município de Laguna Caarapã, é transferida, arbitrariamente, para a área indígena dos Kadiwéu, município de Porto Murtinho. Logram retomar às suas terras, dois anos após. Essas duas áreas foram, em 1984, as primeiras a serem reconhecidas, legalmente, como de posse indígena pelo Governo, após 1928. (BRAND, 2004, p. 141-2). 
Revista Brasileira de História \& Ciências Sociais - RBHCS

Vol. 13 No 25, Edição Especial de 2021

Nos dois casos estão presentes elementos fundamentais: a ação de retomada fortalecida pela articulação, realizada por meio de assembleia ou não, entre distintos grupos indígenas - ou seja, pela articulação em redes.

Retomando o fio condutor deste artigo - a especificidade do fenômeno da articulação em redes no caso dos movimentos indígenas, e empiricamente no movimento indígena de Mato Grosso do Sul - devemos saber que a rigor a primeira articulação em rede para ação coletiva e luta política indígena é a articulação entre parentelas.

No caso dos povos Guarani Ñandeva-Kaiowá e Terena, de Mato Grosso do Sul, pesquisadores já demonstraram a existência culturalmente de uma relação política antitética entre as parentelas componentes de cada etnia (PEREIRA, 1999, 2004; FERREIRA, 2007).

Assim a articulação entre as parentelas em torno de um objetivo comum, como foi no caso das retomadas e o é das assembleias, superando ou relativamente abstraindo a antítese culturalmente constitutiva das relações entre parentelas, já constitui por si só um fenômeno da ordem do fenômeno das redes - ainda que não seja ainda um fenômeno de formação de rede entre movimentos sociais ou entidades da sociedade civil. Trata-se de uma articulação pela persecução de objetivos comuns entre entidades, as parentelas, independentes entre si, porém que se articulam na luta pela efetivação de direitos. E é esta primeira forma de articulação em rede que abordarei na seção seguinte.

\section{ASSOCIAÇÃO ENTRE PARENTELAS}

No Mato Grosso do Sul, inicialmente, foi a articulação, antes não existente assim com vínculos desta qualidade, entre comunidades indígenas antes relativamente isoladas o fato novo que deu condição de possibilidade ao surgimento dos movimentos indígenas. O primeiro deles, o movimento dos Guarani Ñandeva e dos Kaiowá. 
Revista Brasileira de História \& Ciências Sociais - RBHCS

Vol. 13 No 25, Edição Especial de 2021

\section{Guarani Ñandeva e Kaiowá}

Levi Marques Pereira (2003, p. 142) indica a ampliação e intensificação da comunicação entre comunidades indígenas na virada de década de 1970-80 como fator novo que cria as condições para "o surgimento do movimento social pela demarcação das terras". O papel de o que a teoria dos movimentos sociais chama de "redes" revela-se assim crucial na constituição do movimento indígena de Mato Grosso do Sul.

As reivindicações pelos territórios históricos emergiram em distintos locais. Enquanto permaneceram isoladas, eram facilmente sufocadas. Sua articulação, pois, a formação de sua aliança, deu força inédita à demanda indígena, e marca o surgimento de fenômeno histórico novo, o movimento social Guarani-Kaiowá. Sobre isto Pereira (2003, p. 142-3) afirma:

A atuação das comunidades guarani, exigindo a demarcação de suas terras, emergiu em distintos locais nas últimas décadas. Inicialmente as ações tinham pouca conexão direta entre si e, enquanto fenômenos relativamente isolados, eram muitas vezes neutralizados pelas forças contrárias aos interesses indígenas. A partir da década de 1970, as ações das comunidades submetidas a uma situação comum começam a ganhar visibilidade e articulação. Nesse período também passam a receber o apoio de organizações indigenistas da sociedade civil que iniciam a atuação na região. Assim, as comunidades com problemas de terras começam a ensaiar os primeiros passos buscando uma maior articulação e apoio político mútuo. A continuidade no tempo destas ações é mais um aspecto que aproxima as ações das comunidades guarani de um movimento social.

O movimento social indígena aparece como realidade nova, dedicada a interromper o curso histórico que estava se tomando e reverter a desestruturação infligida aos povos indígenas pela expropriação de suas terras.

As ações isoladas de diversas comunidades guarani em MS, visando assegurar seus direitos às terras que tradicionalmente ocupavam, na forma como haviam predominado até a década de 1970, transformam-se a partir desta data, em eventos políticos capazes de aglutinar populações de várias comunidades. A mudança altera a maneira como, até então, vinha sendo tratado o direito destas comunidades às suas terras. Os líderes procuram reverter a tendência predominante de perda crescente das terras ocupadas por comunidades guarani para as frentes colonizadoras, estabelecendo um ordenamento das relações entre comunidades que permita 
confrontar, com objetividade, o problema comum. A ação política visando a ruptura com a situação vigente e a instauração de uma nova ordem social, a exemplo das ações de reocupação de terras guarani aqui analisadas, são justamente aspectos que entram na caracterização dos movimentos sociais. (PEREIRA, 2003, p. 143).

No momento de seu surgimento, o movimento indígena de Mato Grosso do Sul emerge justamente graças às parcerias, às redes formadas por organizações e movimentos sociais. Complementarmente, podemos afirmar que o movimento indígena Ñandeva e Kaiowá no Mato Grosso do Sul surge graças ao desequilíbrio nas correlações de forças, entre povos indígenas e adversários, causadas por estes que viriam a ser designados posteriormente como parceiros do movimento indígena. Ou seja, a articulação em rede é fenômeno que marca nova etapa histórica, ao criar uma figuração social nova que desequilibra a antiga correlação de forças.

A estratégia de reocupação do tekoha, bem como disso pode-se supor a compleição do movimento Guarani Nandeva-Kaiowá como um todo, é um construto histórico de seu povo e objeto constante de debate e reflexão interna. Igualmente, como veremos mais adiante, o povo Terena desenvolve grande deliberação antes de decidir pela ação de retomada de territórios.

As ações de reocupação dos territórios tradicionais, como estratégia histórica de luta, realizadas pela primeira vez na passagem da década de 1970-80, marcam uma nova relação dos povos Guarani Ñandeva e Kaiowá com o Estado brasileiro, no sentido de superação da tutela e reconhecimento de seus direitos.

O sucesso das ações solidárias das comunidades guarani que participaram da mobilização em torno da demanda da demarcação da terra da comunidade de Pirakuá, serviu como um paradigma para comunidades que enfrentam problemas análogos, inaugurando uma nova fase na relação dos guarani com os fazendeiros que com eles disputam a posse das terras, com as Ongs que os apoiam e, principalmente, com o órgão indigenista oficial - FUNAI. Os líderes das comunidades cujas terras ainda não foram reconhecidas e demarcadas pelo Estado, denominadas por eles como "áreas de conflito", constataram, a partir da experiência de Pirakuá, que a garantia de suas terras só virá se forem capazes de mobilizar o apoio de outras comunidades guarani, de setores do indigenismo e da sociedade civil. (PEREIRA, 2003, p. 140-1, grifo meu). 
Revista Brasileira de História \& Ciências Sociais - RBHCS

Vol. 13 No 25, Edição Especial de 2021

Tais ações de retomada de terras, conquanto o movimento social indígena não se reduza a elas, marcam a emergência do movimento sociopolítico Kaiowá e Guarani Ñandeva e, por consequência, uma das raízes do movimento indígena em Mato Grosso do Sul. A forma da ação coletiva criada nessa região e nesse momento tornou-se paradigmática das formas das ações coletivas de outros movimentos indígenas no estado: além dos Kaiowá e Guarani Nandeva, os Terena, no início dos anos 2000, decidiriam em assembleia pela estratégia da retomada.

A mesma constatação dos Guarani Ñandeva e dos Kaiowá de que a garantia de suas terras só viria se mobilizassem o apoio de outras comunidades, de setores do indigenismo e da sociedade civil está igualmente na base da decisão dos Terena pelo recurso à estratégia de mobilização conjunta articulada e retomada como forma de pressionar pela garantia de seus territórios. É importante lembrar que a decisão pela ação de retomada não é nada fácil, pois comporta muitos riscos e perigos. Tanto que os povos indígenas no estado só fizeram recurso a ela quando constataram que os processos de demarcação estavam totalmente paralisados. Portanto, como último recurso.

O segundo momento ou nível na articulação em redes dos movimentos indígenas de Mato Grosso do Sul é quando a ação voltada para a formação de redes de um movimento social já constituído de determinada etnia alcança outros povos em processo de resistência étnica e os fortalece na formação de um movimento social. Assim o caráter articulatório em forma de redes do movimento social dos povos indígenas do estado atuou incentivando, fortalecendo e dando condição de possibilidade para outros povos indígenas organizarem-se em movimento social, ou seja, a forma societária da rede deu condição de possibilidade para a emergência de outros movimentos sociais indígenas no estado.

\section{Terena}

Como vimos, o primeiro povo a organizar sua resistência étnica na forma de movimento social foram os povos Guarani e Kaiowá, na virada da década de 197080. O movimento Guarani-Kaiowá cresceu e fortaleceu-se de lá para cá, e neste processo, criou condições e deu apoio para a transformação da resistência étnica em 
Revista Brasileira de História \& Ciências Sociais - RBHCS

Vol. 13 No 25, Edição Especial de 2021

movimento social de outros povos indígenas no estado, como o povo Terena, cujas raízes da mobilização sociopolítica datam de 2003 e se consolida definitivamente em movimento social em 2012, com a realização da primeira Grande Assembleia do Povo Terena. Na ocasião da realização desta mesma assembleia os Terena reconheceram como a organização da Assembleia Terena inspirou-se na Aty Guasu e contou com a participação de lideranças Guarani-Kaiowá.

Conforme Eloy Amado, uma das lideranças Terena, a primeira Grande Assembleia do Povo Terena foi pensada e articulada pelos seus organizadores tendo como referência a Aty Guasu, realizada então já há três décadas, e toda sua experiência histórica.

Desde as primeiras Assembleia Terena o Conselho Aty Guasu Guarani Kaiowá tem participado com número significativo de lideranças, anciões e jovens. A própria estrutura do conselho foi pensada tendo como exemplo o Conselho Aty Guasu e, nas primeiras reuniões as lideranças terena contaram com reflexões importantes trazidas por Otoniel Ricardo, grande liderança Guarani. Outro registro importante é o fato das Assembleias Terena sempre contarem com a participação de lideranças de outros povos indígenas no sentido de compartilhar experiências. Na Assembleia que ocorreu na Terra Indígena Buriti em maio de 2013, os líderes Babau Tupinambá e Nailton Pataxó, ambos do estado da Bahia participaram ativamente das discussões e deram grande contribuições para a luta dos Terena de Mato Grosso do Sul. Fato é que as assembleias terena tem discutido os principais desafios aos direitos dos povos indígenas, tendo pautada a luta em âmbito nacional, sendo seus documentos finais, verdadeiros registros da situação vivenciada pelas comunidades indígenas e expressão de resistência ao modelo de desenvolvimento adotado pelo Estado brasileiro (ELOY AMADO, 2014, p.80).

Andrey Cordeiro Ferreira (2007), narra como o início do século XXI marca uma virada, ou o nascimento dela, da relação do povo Terena com o Estado brasileiro e o poder tutelar, e como em tal transformação houve articulação terena com entidades parceiras. Como registra Ferreira, este período marca o início da realização de assembleias entre as comunidades Terena, para deliberação sobre os destinos do grupo e fortalecimento de sua unidade, para pensar estratégias de fortalecimento, estabelecer objetivos para educação e exigências para saúde e segurança. A realização de assembleias marca o esforço do grupo de pensar a si 
Revista Brasileira de História \& Ciências Sociais - RBHCS

Vol. 13 No 25, Edição Especial de 2021

mesmo, a própria condição social e seu destino de forma autônoma e autocentrada. Podemos incialmente dizer que representam um esforço em direção à autonomia; no caso Terena portanto, uma oposição ao poder tutelar.

A resistência indígena assumiu diferentes formas - cotidianas e abertas - e hoje [2007] o que parece ser mais expressivo entre os Terena é o desenvolvimento da política de resistência cotidiana ao regime tutelar - ou a seus principais efeitos de poder. Os índios Terena hoje disputam o controle de recursos materiais e posições de poder, tentando afirmar a capacidade política indígena de controlar sua própria vida. Disputam também narrativas históricas e fazem a critica dos estigmas sobre o índio (representações românticas, imagem de preguiçoso e etc) e do conjunto de mecanismos concretos e simbólicos institucionalizados pelo regime tutelar. (FERREIRA, 2007, p. 1).

O início do século XXI é o período que marca o desenvolvimento de formas de resistência abertas, especialmente as assembleias e retomadas. É assim que Ferreira identifica, entre 2001 e 2006, apesar da não existência de um movimento social terena, a existência já de um processo deliberativo colocado em curso pelo grupo, que visava a discutir em conjunto sua situação social e especialmente a situação das paralisadas demarcações de terras; tal processo deliberativo desembocou em ações de retomadas. As ações de retomadas de terras promovidas pelas comunidades indígenas em geral representam igualmente às assembleias a afirmação da autonomia das comunidades frente ao Estado nacional, ou seja, uma oposição ao poder tutelar. Neste aspecto, movimentos indígenas rebelam-se contra o poder tutelar e não adotam mais a postura de esperar do Estado nacional a garantia de seus direitos.

A primeira reunião de caráter deliberativo foi realizada em 2003. Esta reunião foi organizada com apoio do Conselho Indigenista Missionário - CIMI, a pedido dos caciques Terena. Desde a primeira reunião deliberativa Terena já observa-se a articulação com entidades da sociedade civil aliadas. A esta reunião se seguiram várias outras em curto espaço de tempo. De todas estas reuniões deliberativas o Povo Terena decidiu pela ação de retomada como forma de efetivação de seus direitos e pressão política. Após dois anos de debates e progressivo envolvimento mais amplo 
Revista Brasileira de História \& Ciências Sociais - RBHCS

Vol. 13 No 25, Edição Especial de 2021

de toda a comunidade, no fim de 2005 os Terena realizaram sua primeira ação de recuperação de terra.

As retomadas, tal qual as caracterizam os Terena, consistem na reocupação de seus territórios tradicionais, expropriados pelo processo de colonização. Diante da identificação das terras indígenas pelos laudos da Funai, as retomadas consistem em estratégia de luta política para pressionar a demarcação de terras Terena já devidamente identificadas, face a paralisação das demarcações operada pelo Estado e pelos adversários do movimento indígena via judiciário. (FERREIRA, 2007, p. 1017; ELOY AMADO, 2014).

Em 28/11/2005, tal processo se consolidou: os índios Terena de Cachoeirinha realizaram a retomada que haviam tanto discutido e idealizado. A retomada se deu em 1 das 53 propriedades atingidas pela identificação de terras, na Fazenda Santa Vitória, que faz limites com a aldeia de Babaçu. A área foi batizada de "Acampamento Mãe Terra”. O assentamento começou com vinte famílias (do Babaçu) e a princípio os funcionários da fazenda realizaram ameaças $\mathrm{e}$ intimidações, inclusive disparando armas de fogo contra os acampados. Depois da ocupação, começou uma batalha judicial e política para a permanência dos índios na terra. (FERREIRA, 2007, p. 362).

Em suma, desde o nascimento do movimento sociopolítico Terena, este já manifestou como característica de seu modo de ser a articulação em redes com entidades parceiras. A articulação em rede é, pois, constitutiva da ação de retomada. Ferreira assim a define: "A 'retomada' consiste num processo de mobilização política organizada por lideranças indígenas com o apoio de certos atores que compõem o campo das relações interétnicas, especialmente o CIMI, para ocupar parte das terras tradicionais Terena identificadas pelo GT da FUNAI em 2001" (FERREIRA, 2007, p. 358).

Ou seja, na realização das reuniões deliberativas pré-retomadas e das próprias retomadas o Povo Terena se articulou em redes com outras entidades da sociedade civil. E esta articulação segue sendo uma característica do movimento sociopolítico Terena, tanto que desde a realização de sua primeira assembleia já convidaram lideranças indígenas de outras etnias e entidades da sociedade civil e setores do Estado para participar dos debates e refletir em conjunto, diante das possibilidades 
Revista Brasileira de História \& Ciências Sociais - RBHCS

Vol. 13 No 25, Edição Especial de 2021

abertas por estas alianças, sobre a situação do grupo e as estratégias políticas possíveis.

Um momento importante, tido como primeira reunião ocorreu na aldeia Água Branca em março de 2012 tendo como principais articuladores os terena Lindomar Ferreira, Luiz Henrique Eloy, Elvisclei Polidório, Dionédson Candido e Zacarias Rodrigues, estando presentes várias lideranças da terra indígena Taunay/Ipegue (ex-caciques, rezadores, professores indígenas, acadêmicos, movimento de mulheres) e lideranças da Comunidade Mãe Terra do município de Miranda. A reunião contou com a participação de representantes do Ministério Público Federal, o Procurador Emerson Kallif Siqueira; representante da Advocacia Geral da União, a Procuradora Federal Adriana de Oliveira Rocha e Assessoria Jurídica do Conselho Indigenista Missionário, Advogado Rogério Batalha. Foi neste episódio que foi constituída uma comissão de lideranças com o fito de levar a mesma discussão para as demais comunidades, foi constituída a denominada Comissão Fundiária (...). (ELOY AMADO, 2014, p. 74).

A participação de aliados nas assembleias, que significa a confirmação da articulação em rede, abre possibilidade tanto de uma reflexão mais completa e totalizante da condição do grupo, quanto de elaboração e execução de estratégias políticas novas.

\section{Kinikinau}

Assim como o Povo Terena, o Povo Kinikinau também transformou sua forma de resistência até então para a forma de movimento social a partir da participação em encontros e reuniões dos movimentos indígenas a nível nacional e regional e nas Assembleias Terena, ou seja, a partir da articulação em rede com o movimento sociopolítico Terena.

Os Kinikinau se inserem no movimento indígena no início do século XXI, exigindo reconhecimento étnico e território próprio.

A participação dos Kinikinau no I Encontro Nacional de Povos Indígenas em Luta pelo Reconhecimento Étnico e Territorial, em 2003, em Olinda, marca simbolicamente a sua presença no movimento indígena nacional. No mesmo ano participam, em Corumbá, Mato Grosso do Sul, de um outro encontro, do qual resultou a Carta Kinikinawa, documento no qual o grupo de posiciona frente ao Estado brasileiro, exigindo o seu reconhecimento étnico e o direito a um território próprio. No ano seguinte, com a 
Revista Brasileira de História \& Ciências Sociais - RBHCS

Vol. 13 No 25, Edição Especial de 2021

parceria da Secretaria de Educação do Estado de Mato Grosso do Sul, promovem o I Encontro dos Kinikinau, na cidade de Bonito, aproximadamente $70 \mathrm{~km}$ da sua aldeia (São João), situada na Reserva Indígena Kadiweu, em Porto Murtinho. Nesse encontro, tratou-se principalmente da necessidade de preservação da sua cultura através da valorização da língua e da criação de uma escola própria, com um programa adequado às necessidades do grupo. Revelou-se, também, a preocupação com a questão do direito à terra, uma vez que vivem em território que pertence aos Kadiweu. (CASTRO, 2010).

A participação dos Kinikinau em atividades dos movimentos indígenas já consolidados foi fator histórico decisivo para a organização Kinikinau de sua resistência em um movimento social. Ou seja, a articulação em rede dos movimentos indígenas é fator a tal ponto significativo na mobilização sociopolítica indígena que é capaz de impulsionar o nascimento de novos movimentos sociais organizados por outros grupos étnicos.

\section{O CÓDIGO DA REDE}

Um dos fatores decisivos que dá condição de possibilidade para a articulação em rede dos movimentos indígenas em Mato Grosso do Sul, e para o nascimento de novos movimentos articulados a esta rede, é terem sido atingidos por um mesmo processo de violência que os agrediu de igual maneira.

Todas as comunidades comungam a situação do assédio, pressão e violência que representa o contato com as frentes colonizadoras. Este fenômeno está na base do surgimento de uma consciência de participação em uma história comum, aproximando comunidades distintas em torno de um mesmo problema: a perda do espaço físico necessário à reprodução física e cultural da sociedade, de acordo com sua estrutura social e princípios cosmológicos. (PEREIRA, 2003, p. 142).

A vitimação por um mesmo fator desestruturador está na base da constituição do sentimento de identidade coletiva do movimento social. A identidade do movimento social assim é essencialmente diferente da identidade étnica. Não há necessária relação de correspondência entre elas. $\mathrm{O}$ que significa também que a identidade do movimento social pode ser compartilhada por diferentes etnias. 
Revista Brasileira de História \& Ciências Sociais - RBHCS

Vol. 13 No 25, Edição Especial de 2021

Tonico Benites também indica a ação violenta externa como razão da reação e da mobilização indígena: "estas práticas de despejo de tekoha geravam situações de reação, perplexidade, aflição e constrangimento entre as famílias indígenas, que por isso começaram a se articular para retornar ao tekoha" (BENITES, 2014, p. 21). A história comum, que exige uma resposta comum e cada vez mais coordenada, faz as vezes de código de comunicação compartilhado para a formação e expansão da rede de alianças.

\section{REDES DE ALIANÇAS ENTRE MOVIMENTOS SOCIAIS DE DIFERENTES POVOS INDÍGENAS}

O próximo nível na escala é a articulação entre movimentos indígenas de diferentes grupos étnicos, configurando, aí sim, ao pé da letra uma rede de movimentos sociais. Grupos étnicos diferentes e por vezes mesmo antagônicos articulam-se no escopo de atuação do movimento social, na esfera de atuação pela persecução da demanda comum levantada pelos grupos.

Para o caso dos movimentos étnicos, como se vê na formação e atuação contemporânea do movimento indígena de Mato Grosso do Sul, a formação do movimento indígena abstraiu, na amplitude necessária para formação das alianças, as diferenças étnicas. Para os movimentos étnicos, e para o movimento indígena de Mato Grosso do Sul, a articulação entre diferentes etnias a rigor já pode ser considerada um tipo de rede. É também esta articulação inicial que devemos ter em mente quando pensarmos sobre o surgimento do movimento indígena de Mato Grosso do Sul.

A aliança pluriétnica é uma novidade sócio-histórica e marca a realidade do movimento indígena no estado e no país. "Essa rede formada a partir das demandas solicitadas vai além da identificação étnica em alguns momentos, pois não é rara a união entre os Guarani, os Kaiowá e os Terena para solicitarem melhoria na condição de vida dos povos. Exemplo disso foi a união entre Domingos Verissimo e Marçal de Souza na década de 1980" (ALMEIDA, 2012, p. 52).

Dito isto, a articulação política destes povos, em movimentos sociais autônomos articulados, se realiza com base em certa abstração das diferenças 
Revista Brasileira de História \& Ciências Sociais - RBHCS

Vol. 13 No 25, Edição Especial de 2021

étnicas. Na constituição, pois, do movimento social a articulação em rede pelo fortalecimento da demanda supera as diferenças étnicas. Vejamos como exemplo inicial disto o caso dos grupos étnicos Guarani Ñandeva e Kaiowá, que malgrado a percepção errônea que a sociedade envolvente tem deles como pertencentes a um mesmo grupo, são na verdade grupos étnicos distintos, que no entanto, articulam-se numa força social única.

Em Mato Grosso do Sul vivem os Kaiowa e os Guarani Ñandeva. É muito comum ouvir pessoas de vários meios sociais, incluindo a imprensa, acadêmicos e governos, referirem-se a estes grupos como sendo Guarani-Kaiowa, conotando a ideia de que os Guarani Ñandeva e os Kaiowa são um mesmo grupo étnico. No entanto, somente os Ñandeva é que se autodenominam como Guarani. De fato, o que se tem são dois grupos distintos que frequentemente, a contragosto, são tratados como se fossem um. A única exceção para isso está em seu uso político. Quando é politicamente interessante, como expressão de uma luta comum, as lideranças utilizam o designativo Guarani Kaiowá (CAVALCANTE, 2013, p. 21).

Podemos extrapolar para os movimentos indígenas de Mato Grosso do Sul como um todo o processo de identificação política descrito por Thiago Cavalcante (2013, p. 21) especificamente para os Guarani Ñandeva e para os Kaiowá: “Quando é politicamente interessante, como expressão de uma luta comum, as lideranças utilizam o designativo Guarani Kaiowá”. Para o caso dos povos indígenas em Mato Grosso do Sul, quando a referência é a expressão de uma luta comum, usam o designativo movimento indígena.

No contexto de fortalecimento da própria luta e formação de alianças, os grupos indígenas de Mato Grosso do Sul, confirmando as características descritas pelo conceito de etnopolítica (CONTRERAS, 2008), alinham-se formando um movimento identitário único, à parte suas diferenças étnicas. Tal fato evidencia-se quando nos discursos de lideranças indígenas a referência é crescente ao 'movimento indígena', menos do que ao movimento formado pela etnia a que se pertence. Tratase mais nos discursos de defender o 'direito dos indígenas', assim de forma genérica, do que de defender o direito tão só de sua etnia.

Os diferentes povos indígenas, com diferentes formações étnicas e diferentes histórias de resistência ao avanço colonial, têm articulado tendencialmente nos 
Revista Brasileira de História \& Ciências Sociais - RBHCS

Vol. 13 No 25, Edição Especial de 2021

últimos tempos suas demandas de forma unificada. Tal fator pode ser lido como outro resultado da articulação em rede dos povos indígenas do estado e seus respectivos movimentos. Todas estas articulações, novidadeiras na história cultural dos povos indígenas, primeiro entre parentelas de um mesmo povo em seguida entre distintos povos, correspondem a uma forma de ação em rede, uma integração com base no compartilhamento de um mesmo código comunicativo.

Na seção seguinte discutirei outra dimensão importante da articulação em rede do movimento indígena de Mato Grosso do Sul, sua articulação com entidades da sociedade civil aliadas à causa do movimento. Estas alianças formadas, ou seja, aqueles ativistas externos ao movimento indígena que passam a falar e a atuar em nome da causa, combatendo a hegemonia capitalista e racista, e trabalhando para ampliar e fortalecer a força social em favor da demanda indígena.

As alianças desempenham para os movimentos sociais em geral funções diversas, conforme as necessidades do movimento e o contexto. Para o caso do movimento indígena de Mato Grosso do Sul, as alianças ou redes, desempenharam um papel maior que auxiliar o movimento: deram a condição de possibilidade própria do surgimento do movimento.

\section{REDES DE ALIANÇAS COM ENTIDADES DA SOCIEDADE CIVIL Entidades civis}

O terceiro momento em que podemos identificar o fenômeno das redes no movimento indígena de Mato Grosso do Sul é na articulação dos grupos indígenas com entidades da sociedade civil, como o Conselho Indigenista Missionário (CIMI), o Projeto Kaiowá Ñandeva, e órgãos do Estado, como Fundação Nacional do Índio (FUNAI) e Ministério Público Federal.

As alianças com outros setores sociais são fator determinante do surgimento, da consolidação e da atuação contemporânea do movimento indígena nacional e estadual. Nisto, se se considerar a análise de Castells, não se diferindo da atuação regular dos movimentos sociais em geral do último quartel do século XX para cá, na era da informação. Porém de uma forma específica, a articulação do movimento indígena - não tanto com outros movimentos sociais, porém especialmente - com as 
Revista Brasileira de História \& Ciências Sociais - RBHCS

Vol. 13 No 25, Edição Especial de 2021

instituições parceiras, como uma das poucas reações possíveis nas circunstâncias que os contornavam.

Para o caso dos Guarani Ñandeva e dos Kaiowá, as reocupações de terra, como principal estratégia dos movimentos indígenas, é descrita por Benites como um processo cumulativo de longa duração com protagonismo das famílias indígenas, porém com atuação de suporte de diversas instâncias não pertencentes ao movimento indígena mas aliadas da causa.

Neste capítulo são analisadas as situações de reocupação pelas lideranças políticas e espirituais dos Aty Guasu nas últimas três décadas, configurando um processo cumulativo e em expansão no qual atuam não apenas os indígenas, mas também as agências oficiais (Funai, Polícia Federal, Ministério Público Federal, tribunais de justiça federais e estaduais, prefeituras, associações de produtores rurais, etc.), organizações não-governamentais (como Projeto Kaiowa e Ñandeva), Conselho Indigenista Missionária (CIMI) vinculado à igreja católica, além de antropólogos, universidades, imprensa, movimentos sociais, etc. (BENITES, 2014, p. 28).

Para o caso Terena, a articulação de suas assembleias contou com apoio, à medida do solicitado pelos caciques, do CIMI, aliança histórica do movimento indígena na região. Assim o parceiro desempenhou papel importante dando suporte no momento de emergência do protagonismo Terena e seu movimento social.

No tempo de surgimento do movimento social indígena, então especificamente Guarani-Kaiowá, na virada da década de 1970-80, dois parceiros se destacam: o Conselho Indigenista Missionário (CIMI), cuja atuação é viva e forte ainda hoje, e o Projeto Kaiowá-Ñandeva, muito importante durante vinte anos, apesar de desativado hoje. O escopo de atuação de cada uma dessas instituições é grande. Quanto especificamente à sua relação com o movimento indígena, na época citada atuaram fortalecendo a cidadania indígena, com o que estes decidiram por se mobilizar.

No início do movimento indígena, no final da década de 1970, atuavam na região as seguintes instituições: CIMI, PKÑ e OPAN (Operação Anchieta, hoje Operação Amazônia) e as universidades. Essas organizações tinham o objetivo principal de fortalecer politicamente os indígenas para que os próprios buscassem seus direitos. Como já descrevi, tal objetivo foi cumprido, pois ajudaram 
Revista Brasileira de História \& Ciências Sociais - RBHCS

Vol. 13 No 25, Edição Especial de 2021

a criar movimentos que atuam até os dias atuais. (ALMEIDA, 2012, p. 46).

O Conselho Indigenista Missionário trata-se de um setor da Igreja Católica dedicado a dar amparo aos povos indígenas. Foi criado em 1972 no contexto do movimento da Teologia da Libertação, e da preocupação da Igreja Católica com as populações do campo no Brasil, contexto no qual também foi criada a Comissão Pastoral da Terra.

A criação do CIMI em 1972 oficializa o setor da Igreja Católica como o defensor dos grupos étnicos no Brasil. O pano de fundo para a criação do CIMI era o cenário de descaso no qual o Estado se relacionava com os povos indígenas. Durante mais de 30 anos o CIMI vem desenvolvendo várias ações com os indígenas na região. (ALMEIDA, 2012, p. 47).

Conforme Almeida, o CIMI foi muito presente e teve ampla atuação na trajetória do movimento.

o CIMI também atuou fazendo pressão nas instituições para que as mesmas cumprissem a legislação que beneficiava os indígenas. $\mathrm{O}$ CIMI atuou na educação escolar, e nos Aty Guasu, nas Nemboaty Guasu, nas mobilizações de retomadas das Terras Tradicionais, nas comitivas dos indígenas para Brasília no período pré-Constituição de 1988, sempre atuando junto e apoiando o Movimento Indígena. (ALMEIDA, 2012, p. 47).

Já o Projeto Kaiowá-Ñandeva "atuou na região por quase 20 anos. (...) O Projeto Kaiowá-Ñandeva pode ser resumido como uma ação que visava a produção de alimentos básicos para os indígenas das aldeias nas quais atuava” (ALMEIDA, 2012, p. 48).

\section{Antropologia}

A comunidade antropológica, aliás, desempenha importante papel como parceira do movimento indígena no Brasil todo e em Mato Grosso do Sul, e desempenhou papel especial na Constituinte de 1988. Sobre ela, Eduardo Viveiros de Castro fala como a comunidade antropológica se opôs ao projeto de emancipação, integração e assimilação, feita política pública do Estado ditatorial brasileiro, dos 
Revista Brasileira de História \& Ciências Sociais - RBHCS

Vol. 13 No 25, Edição Especial de 2021

povos indígenas e lutou rumo à consagração dos direitos indígenas na Constituição de 1988.

A comunidade antropológica, por via de suas ABAs (Associação Brasileira de Antropologia) e similares, desempenhou um papel fundamental na decisão de botar o pé na porta e impedir o projeto de emancipação, decisão tomada em conjunto com outros advogados da causa e, naturalmente, com os índios. (VIVEIROS DE CASTRO, 2007, p. 142).

Após a promulgação da Constituição coube aos antropólogos o papel de peritos especialistas a informar o judiciário na tarefa de oficializar os direitos indígenas.

Em todo o processo de juridificação da questão “quem é índio?”, isto é, de decidir como e onde aplicar os artigos da Constituição de 1988, a antropologia conseguiu, a meu ver com toda a justiça, esse ganho político de se tornar um interlocutor legítimo do aparelho de Estado, parte necessária nos processos jurídicos de garantia e de oficialização das demarcações de terra, entre outras coisas. (VIVEIROS DE CASTRO, 2007, p. 143).

Viveiros de Castro contesta a necessidade da institucionalização jurídica da figura de um perito para dizer se alguém é ou não é indígena: “Ao antropólogo não somente não cabe decidir o que é um a comunidade indígena, que tipo de coletivo pode ser chamado de comunidade indígena, como cabe, muito ao contrário, mostrar que esse tipo de problema é indecidível" (VIVEIROS DE CASTRO, 2007, p. 145). Mas diante desta necessidade imposta na arquitetura jurídica nacional, os antropólogos a realizaram.

A FUNAI atua como parceira do movimento indígena na parte logística das reuniões e assembleias (ALMEIDA 2012, p. 49), na realização dos laudos antropológicos e dos processos de reconhecimentos territoriais. O Ministério Público Federal constitui-se em mais um grupo de pressão para fazer cumprirem-se as leis e direitos dos povos indígenas (ALMEIDA 2012, p. 50). Vale lembrar, a atuação destas instituições é ampla com os povos indígenas. Todavia, o que digo aqui procura restringir-se à relação destas instituições com o movimento indígena especificamente, sabendo que a atuação geral delas junto aos povos indígenas cobre um escopo muito maior. Estes 
Revista Brasileira de História \& Ciências Sociais - RBHCS

Vol. 13 No 25, Edição Especial de 2021

parceiros formam a rede, parte do ambiente político no qual se move o movimento indígena.

Nesse contexto, os Guarani e Kaiowá passaram a reivindicar do Estado brasileiro o reconhecimento, a demarcação e a proteção de parte de seu território como terra indígena. A política adotada pelo governo federal, a quem cabe proceder ao reconhecimento e a proteção destas terras, por muito tempo foi de leniência e desdém. Os avanços obtidos, só o foram por força da luta dos indígenas e pelo comprometimento de raros antropólogos, indigenistas ou cidadãos simpáticos à causa, que atuaram dentro ou fora dos aparelhos estatais. (CAVALCANTE, 2013, 401).

A atuação de forma original dos parceiros do movimento tem o poder de transformar o campo sociopolítico no qual o movimento age e de forçar mudanças históricas. A respeito disso, podemos ver a atuação do Ministério Público Federal que, quando adquiriu nova forma, intensificada, interferiu diretamente na conjuntura.

Uma nova conjuntura nacional se delineou a partir de 2005, com uma intervenção mais forte do Ministério Público Federal exigindo que a FUNAI retomasse o processo administrativo de identificação e delimitação de terras para os indígenas acampados em pequenas áreas reocupadas dos tekoha tradicionais ("nas fazendas") e beiras de estrada (BENITES, 2014, p. 248).

No que concerne ao estabelecimento e fortalecimento de redes, as assembleias ocupam posição de destaque inclusive na formação de parcerias do movimento, desde o seu surgimento, posição que mantêm com o passar do tempo.

a importância do Aty Guasu não pode ser medida isoladamente pelo seu sucesso em propiciar formas de resistência aos despejos por parte das famílias Guarani e Kaiowá. Desde o início dos anos 80 nos Aty Guasu os líderes religiosos foram assumindo posições proeminentes nas assembleias do Aty Guasu e na construção de uma articulação crescente entre as famílias indígenas despejadas (Ñomoiru ha Pytyvõ). (BENITES, 2014, p. 248-9).

\section{Setores do Estado}

Além destas duas instituições devemos citar no rol das parcerias, das redes, instituições estatais que ajudaram a constituir "uma base para atuação das mobilizações indígenas, entre elas as universidades, o Ministério Público Federal e a 
Revista Brasileira de História \& Ciências Sociais - RBHCS

Vol. 13 No 25, Edição Especial de 2021

FUNAI. Essas parcerias se constituíram em assessorias jurídicas, logísticas e de formação política para os grupos étnicos” (ALMEIDA, 2012, p. 46).

As universidades, como por exemplo a atual Universidade Federal da Grande Dourados, antiga Universidade Federal de Mato Grosso do Sul - Campus de Dourados, e a atual Universidade Católica Dom Bosco, por meio de seus quadros docentes aliados à causa indígena, desenvolveram cursos de graduação em parceria com o movimento indígena, cursos para formação de professores indígenas, ações afirmativas nas graduações e pós-graduações para estudantes indígenas.

A atuação individual de professores nem por isso pode deixar de ser mencionada. Seja por meio de artigos na imprensa, seja pelo ensino e pesquisa preocupados com pensar a causa indígena, compreender e evidenciar suas determinações, as demandas do movimento, desvendar fatos históricos esquecidos e ou negados.

\section{CONSIDERAÇÕES FINAIS}

As redes de alianças são condição de possibilidade para a formação do movimento indígena de Mato Grosso do Sul. Não são condição de possibilidade para sua resistência cotidiana - nos termos de Scott (2002). A resistência pode existir antes da rede, e assim o foi para toda a América indígena; mas, para o caso de Mato Grosso do Sul, a transformação da resistência na forma específica de movimento social só foi possível a partir da articulação em rede.

A articulação de redes de alianças - entre diferentes povos indígenas, e entre grupos indígenas e entidades da sociedade civil parceiras - pelos povos indígenas de Mato Grosso do Sul está entre os antecedentes sociológicos diretos do surgimento do movimento sociopolítico indígena no estado. Isto quer dizer que sem a articulação em redes de alianças a resistência dos povos talvez não tomasse a forma de movimento social naquele momento. Vale lembrar que não há nenhum juízo de valor na apreciação sociológica da forma de resistência dos povos indígenas, se calcada em "processos de resistência étnica" (FERREIRA, 2007, p. 9), cotidianas ou abertas, ou se calcada em um movimento sociopolítico (GONZÁLEZ, 2010). 
Revista Brasileira de História \& Ciências Sociais - RBHCS

Vol. 13 No 25, Edição Especial de 2021

A forma sociológica movimento social é escolhida por grupos em condição de subalternidade social pois combina relação de força com relação de sentido. Não se trata de apenas argumentação, apelo à razão diante das relações de força que sustentam as desigualdades sociais. Não se trata igualmente de pura força sem significado, sem construção de sentido, por si incapaz de contestar as representações sociais que legitimam a desigualdade e tentam justificar a condição subalterna destes grupos. A forma sociológica de resistência e luta movimento social combina produção de força social, material - lembrando o dizer de Melucci (1989) de que os "movimentos sociais são força social em movimento" -, na forma das ações coletivas do movimento - no caso do movimento indígena, as retomadas, os bloqueios de rodovias, as manifestações públicas -, e produção de sentido, de conjuntos de significados que denunciem e contestem a desigualdade e a injustiça social de que são vítimas - no caso, a ação dos intelectuais indígenas e de intelectuais nãoíndigenas e entidades parceiras, que contestam a injustiça, recontam uma história até então contada somente da perspectiva do opressor, divulgam e debatem estas novas representações sobre a realidade social e histórica e o conflito em jogo, como forma de conquistar a sociedade em geral para a legitimação da cidadania indígena.

Outrossim, a forma movimento social é meio de contestar a criminalização das ações do grupo social em posição vulnerável, a quem só resta historicamente ações subversivas e confrontantes incluso do arcabouço jurídico-legal, à medida em que este é comprometido ou permissivo com a conservação do desequilíbrio social que gera a situação de vulnerabilidade destes grupos. As ações subversivas assim a partir da assunção da forma sociológica de movimento social, acompanhada do trabalho necessário de legitimação, evitam a criminalização da demanda e da ação, subversiva, dos grupos vulneráveis, e problematizam incluso essa criminalização. A ação contra uma ordem social injusta é necessariamente, como não poderia deixar de ser, subversiva, assim correndo o risco de ser tachada como criminal. A ação contra uma ordem social injusta encampada por um movimento social tem por razão de ser romper com a criminalização, e legitimar a ação do movimento como ação preocupada com o estabelecimento da justiça social. O "desocultamento da opressão" (SOUZA SANTOS, 1995) é um esforço, pois, de luta simbólica, de luta no 
Revista Brasileira de História \& Ciências Sociais - RBHCS

Vol. 13 No 25, Edição Especial de 2021

campo das representações, pelo poder de impor representações legítimas ao todo da sociedade.

A articulação em redes é uma característica dos movimentos indígenas em geral. Investigadores especializados na interpretação dos movimentos indígenas latino-americanos, como Catherine González, já identificaram esta forma associativa dos movimentos indígenas, todavia, referindo-se a ela como a criação de "alianças duradouras com outros setores sociais" (GONZÁLEZ, 2010).

A criação de alianças assim é característica constitutiva dos movimentos indígenas latino-americanos. Aparentemente esta escolha do movimento por esta forma associativa pelos povos indígenas não teve, inicialmente, como causa os mesmos fenômenos que engendraram e condicionam a sociedade informacional. Duas hipóteses podem ser inicialmente ser formuladas para explicar esta articulação em redes de alianças dos movimentos indígenas de Mato Grosso do Sul.

Primeiro a condição de excepcional desestruturação e vulnerabilidade dos povos indígenas no estado, causada pela expropriação do território, pelo seu confinamento em reservas, pela exploração de sua força de trabalho de forma degradante, pela violência perpetrada pelas forças colonizadoras, pela tutela. Tal condição colocou para as lideranças indígenas a necessidade histórica de articularse em redes primeiramente entre as próprias parentelas constitutivas de cada grupo étnico, cuja relação até então era marcada por relativa antítese; em seguida com entidades da sociedade civil, como o CIMI, o Projeto Kaiowá Ñandeva, setores do Estado, como as alas progressistas da FUNAI e o Ministério Público Federal; e durante todo o tempo, da emergência do movimento até hoje, a articulação entre lideranças indígenas de diferentes etnias e entre os grupos étnicos inteiros, por meio de seus movimentos sociais.

Neste último aspecto do fenômeno da articulação em redes deve incluir-se a formação de alianças com movimentos indígenas distantes, denotando um modo de ser da formação de redes que persegue expansão diametral cada vez maior. É o caso do Acampamento Terra Livre realizado anualmente em frente ao Congresso Nacional em Brasília, e reúne lideranças de movimentos indígenas do Brasil todo; e é o caso do Encontro Intercontinental Guarani, que reuniu indígenas Guarani de 
Revista Brasileira de História \& Ciências Sociais - RBHCS

Vol. $13 \mathrm{~N}^{\circ}$ 25, Edição Especial de 2021

Brasil, Argentina, Paraguai e Bolívia. Tais eventos, além de constituírem em assembleia para troca de experiência e discussão sobre os destinos e estratégias do grupo, constituem fundamentalmente uma formação de rede cada vez mais abrangente, tanto no sentido territorial como no sentido populacional.

Segundo, a necessidade de 'tradução' da resistência indígena, de suas demandas e da forma de buscar a legitimação e efetivação delas para formas próprias do campo político da sociedade nacional. Ou seja, as condições intrínsecas à realização de uma etnopolítica demandam a articulação por parte do grupo étnico de alianças entre determinados setores da sociedade envolvente, como forma de canalizar sua ação política para os termos reconhecíveis e efetivos sobre esta mesma sociedade.

Na etnopolítica em si mesma, se retomarmos a definição de rede em que se assenta a teorização de Castells - o compartilhamento do mesmo código de comunicação - podemos enxergar neste fenômeno a entrada dos movimentos indígenas na sociedade em rede, isto é, na rede globalizada e globalizante constitutiva desta sociedade.

A ação voltada para formação de rede de alianças deu condição de possibilidade para o surgimento do movimento sociopolítico indígena no momento em que surgiu, dada sua fragilidade e dadas as necessidades intrínsecas da etnopolítica, e hoje é esta mesma capacidade de articular redes de alianças que revela caminhos potencialmente poderosos para subversão das correlações de forças a que estão submetidos os povos indígenas no Mato Grosso do Sul.

\section{Referências bibliográficas}

ALMEIDA, Ellen Cristina de. Formas de organização política dos guarani, kaiowá e terena no sul do Mato Grosso do Sul. Trabalho de conclusão de curso (Graduação em Ciências Sociais) - Faculdade de Ciências Humanas, Universidade Federal da Grande Dourados, Dourados, MS, 2012.

BENITES, Tonico. Rojeroky hina ha roike jevy tekohape (Rezando e lutando): o movimento histórico dos Aty Guasu dos Ava Kaiowa e dos Ava Guarani pela recuperação de seus tekoha. Tese (Doutorado em 
Revista Brasileira de História \& Ciências Sociais - RBHCS

Vol. 13 No 25, Edição Especial de 2021

Antropologia Social) - Museu Nacional, Universidade Federal do Rio de Janeiro, Rio de Janeiro, RJ, 2014.

BRAND, Antônio Jacó. Os complexos caminhos da luta pela terra entre os Kaiowá e Guarani no MS. Revista Tellus, v. 4, no 6, p. 137-150, 2004.

CASTELLS, Manuel. The information age: economy, society, and culture. Chichester: Wiley-Blackwell, 2010, 3v.

CASTRO, Iara Quelho de. De Chané-Guaná a Kinikinau: da construção da etnia ao embate entre o desaparecimento e a persistência. Tese (Doutorado em Ciências Sociais) - Instituto de Filosofia e Ciências Humanas, Universidade Estadual de Campinas, Campinas, SP, 2010.

CAVALCANTE, Thiago Leandro Vieira. Colonialismo, território e territorialidade: a luta pela terra dos Guarani e Kaiowa em Mato Grosso do Sul. Tese (Doutorado em História) - Faculdade de Ciências e Letras, Universidade Estadual Paulista. Assis, SP, 2013.

CONTRERAS, Victor Raul Ortiz. Etnopolítica, territorialização e história entre os Mapuche no Chile e os Kaiowá-Guarani no Brasil: um estudo comparativo. Dissertação (Mestrado em Antropologia Social) - Instituto de Filosofia e Ciências Humanas, Universidade Estadual de Campinas, Campinas, SP, 2008.

ELOY AMADO, Luiz Henrique. Poké'exa ûti o território indígena como direito fundamental para o etnodesenvolvimento local. Dissertação (Mestrado em Desenvolvimento Local) - Universidade Católica Dom Bosco, Campo Grande, MS, 2014.

FERREIRA, Andrey Cordeiro. Tutela e Resistência Indígena. Etnografia e história das relações de poder entre os Terena e o Estado Brasileiro. Tese (Doutorado em Antropologia Social) - Museu Nacional, Universidade Federal do Rio de Janeiro, Rio de Janeiro, RJ, 2007.

GONZÁLEZ, C. Naturaleza política y acciones colectivas de los movimientos sociales, un emblemático caso de movilización indígena. Universitas Humanística, n. 70, pp. 79-100, julio-diciembre 2010.

MELUCCI, Alberto. Um objetivo para os movimentos sociais? Lua Nova, ano 4, n. 17, p. 49-66, junho 1989.

PEREIRA, Levi Marques. Imagens Kaiowá do sistema social e seu entorno. Tese (Doutorado em Antropologia Social) - Universidade de São Paulo, São Paulo, $\mathrm{SP}, 2004$.

PEREIRA, Levi Marques. O movimento étnico-social pela demarcação das terras guarani em MS. Revista Tellus, v. 3, n. 4. p. 137-145, 2003.

SANTOS, Boaventura de Souza. Pela mão de Alice. O social e o político na pós-modernidade. São Paulo: Cortez, 1995. 
Revista Brasileira de História \& Ciências Sociais - RBHCS

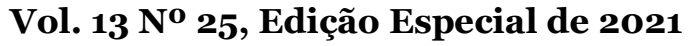

SCOTT, J. C. Formas cotidianas da resistência camponesa. Raízes: Revista De Ciências Sociais E Econômicas, 2002, 21(1), 10-31.

SOUZA, Rosaldo de Albuquerque. Sustentabilidade e processos de reconstrução identitária entre o povo indígena Kinikinau (koinukunôen) em Mato Grosso do Sul. Dissertação (Mestrado em Desenvolvimento Sustentável) - Centro de Desenvolvimento Sustentável, Universidade de Brasília, Brasília, DF, 2012.

TOURAINE, Alain. Critique de la modernité. Paris: Les Éditions Fayard, 1992. VIVEIROS DE CASTRO, Eduardo. Encontros. Organização de Renato Sztutman. Rio de Janeiro: Beco do Azougue, 2007.

Recebido em Agosto de 2020 Aprovado em Fevereiro de 2021

DOI: https://doi.org/10.14295/rbhcs.v13i25.11854 